\title{
Force distribution in self-tapping screws: experimental investigations with fibre Bragg grating measurement screws
}

\author{
Timo Claus $^{1}$ D $\cdot$ Werner Seim $^{1} \cdot$ Johannes Küllmer ${ }^{1}$
}

Received: 14 September 2020 / Accepted: 28 July 2021 / Published online: 17 August 2021

(c) The Author(s) 2021

\begin{abstract}
The pull-out resistance of fully threaded, self-tapping screws under axial loading has been investigated intensively in the past. Actual design models are based mainly on empirical data because the detailed interaction between the screw thread and the surrounding timber member remains unclear and might depend on the test set-up. An innovative screw sensor with 19 internal fibre Bragg gratings (FBGs) was developed to measure the forces along the screw axis. The screw diameter was $12 \mathrm{~mm}$ and the maximum embedding length was $360 \mathrm{~mm}$. The FBG measurement screw was applied in pull-out tests under different support conditions. The results carried out show details of the axial forces along fully threaded screws depending on the magnitude of the screw axis to grain angle, the embedding length, the material and the support conditions. Load transfer between the screw and the surrounding timber was determined by means of the change of axial forces along the screw axis. A comparison of the experimental results with Volkersen's theory points out the decisive dependency of the support conditions on the axial forces in fully threaded self-tapping screws. Additionally, the experimental test results show indications of shear and compressive stresses in the interface of the measurement screw.
\end{abstract}

\section{Introduction and background}

Self-tapping screws are typically used for connections between timber parts together with or without steel plates. Moreover, fully threaded screws are used as a reinforcement against longitudinal shear in glued laminated timber (GLT) or cross-laminated timber as studied by Dietsch et al. (2013) or tensile failure perpendicular to the grain in laterally loaded dowel-type connections (see Beijtka 2005; Uibel and Blaß 2006; Wolfthaler and Augustin 2016). Axial and lateral forces in the screw might also be induced if tension forces perpendicular to the grain occur caused by geometry in the case of notches, as shown by Jockwer (2015), or holes in beams, investigated by Danzer et al. (2016), or in the case of swelling and shrinkage of the timber (Dietsch and Brandner 2015; Danzer et al. 2020). Self-tapping screws are most effective when loaded in the axial direction. The axial load capacity in Eurocode 5 (2010) is limited by the withdrawal capacity of the thread, the pull-through capacity of the screw head and the tensile capacity of the steel.

Timo Claus

timo.claus@uni-kassel.de

1 University of Kassel, Kurt-Wolters-Straße 3, 34125 Kassel, Germany
The withdrawal capacity depends on the diameter $d$ and the embedding length $l_{\text {ef }}$ of the screw. Furthermore, the characteristic density of the timber $\rho_{\mathrm{k}}$ and the angle $\Theta$ between the screw axis and grain influence the withdrawal capacity according to Eurocode 5 (2010). This leads to the definition:

$F_{a x, \Theta, R k}=n_{e f} \cdot \frac{0.52 \cdot d^{0.5} \cdot l_{e f}^{0.9} \cdot \rho_{k}^{0.8} \cdot k_{d}}{1.2 \cdot \cos ^{2} \Theta+\sin ^{2} \Theta}$

The factor $n_{\text {ef }}$ considers the effective number of screws and $k_{\mathrm{d}}$ adapts the withdrawal capacity of screws for $d<8 \mathrm{~mm}$.

Different theoretical models for the calculation of the withdrawal capacity based on the evaluation of experimental results have been presented for different screw types and applications as for connections and reinforcements (Blaß et al. 2006; Gehri 2009; Frese and Blaß 2009; Pirnbacher et al. 2012; Ringhofer 2017; Brandner et al. 2018). The empirical-based models provide different prefactors and exponents for the geometrical parameters and material properties.

Compared to the behaviour of glued-in rods, for which bonding behaviour has been studied intensively, for example, in the GIROD project (Aicher et al. 1999; Gustafsson and Serrano 2000) and later by, for example, Pörtner (2006) and 
Tlustochowicz et al. (2011), only a few mechanical models exist to describe the withdrawal capacity for self-tapping screws. Some investigations were made considering the interaction between screw and surrounding material (Jensen et al. 2011; Ellingsb $\varnothing$ and Malo 2012; Ringhofer and Schickhofer 2014a).

Finite element analysis was performed to study the wood screw interaction and to describe the load deformation characteristic of screws under tension and compression loads (Serrano 2001; Danzer et al. 2016; Naderer et al. 2016) or to consider group effects, as performed by Mahlknecht et al. (2016). The bond behaviour of the model was considered to be homogeneous along the screws shaft together with a simplified load slip behaviour derived from the load-deformation relationship of the screw. The stress distribution along the screw axis was always found to be nonlinear.

Only a few tests have been performed to investigate the bonding interaction experimentally. Ringhofer and Schickhofer (2014a) measured strains on the screw with strain gauges. The strain gauges were applied between the thread of the screw. The test results were modified with a polynomial regression and compared to the results according to Volkersen (1953) for linear-elastic bonding behaviour. The experimental results of the pull-push tests showed a comparatively poor match compared to the prediction according to Volkersen's theory for the investigated slenderness of $l_{\mathrm{ef}} / d=10,15$ and 20 and for different screw axis to grain directions.

An explanation for that might be the influence of the pull-push load configuration resulting in shear stresses as well as compression stresses between the screw and the surroundings, as defined by Ringhofer and Schickhofer (2014b) (Fig. 1).

The direct measuring of strains and forces in self-tapping screws with glued-in strain gauges has already been proposed by Wolfthaler and Augustin (2016), who studied the reinforcement of a dowel connection, and by Danzer et al. (2016) to measure axial forces which develop in reinforcements around holes in glulam beams. The manufacturing process of the measuring screw was comparatively simple, but only two measuring points were possible because of the limiting geometrical conditions, which are the diameter of the pre-drill and the number of cables to be inserted in the pre-drilled hole.

Experimental tests with optical image correlation were performed by Ayoubi and Trautz (2013) to evaluate the strains on the surface of comparatively thin timber specimens in a pull-pull test configuration without reinforcements of a fully threaded screw. The evaluation of the strains on the timber surface pointed out lines of equal principal tension stresses. The information was compared to the results of strain gauges and showed good accordance.

Kumpenza et al. (2020) used the "electronic speckle pattern interferometry" to evaluate the strains in the surrounding area of the screws. Several pull-out tests in a set-up with precut timber specimens were performed in this study. To provide a look inside the timber specimen, only one half of the screw was embedded in the timber to monitor the strains on the timber around the screw. The evaluation of the strains showed strain concentration close to the screw head, which decreased along the penetration length. Thus, a non-constant distribution of stresses was assumed.

The limitation of only a few measurement points inside the screw can be overcome by a new fibre optic measurement technique presented by Schmidt-Thrö et al. (2016) for the reinforcement of structural concrete. The optical fibre was glued into the reinforcement and could be used for continuous strain measuring. The method showed similar results compared to that with strain gauges, but new effects of the load distribution in the interface between steel and concrete were visible.

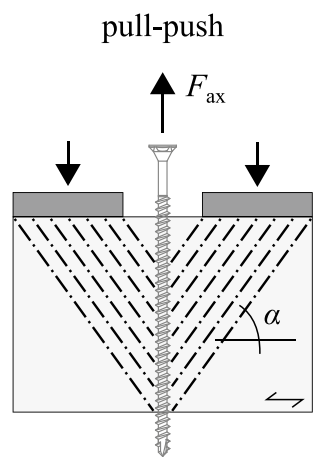

(a)

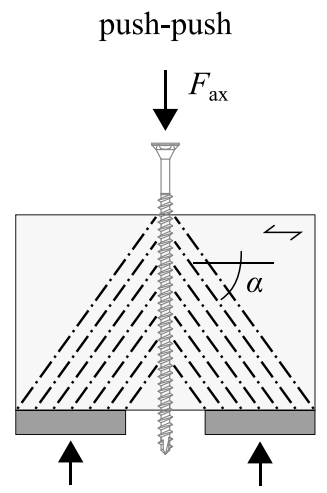

(b)

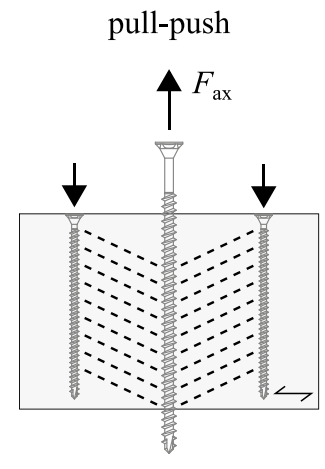

(c)

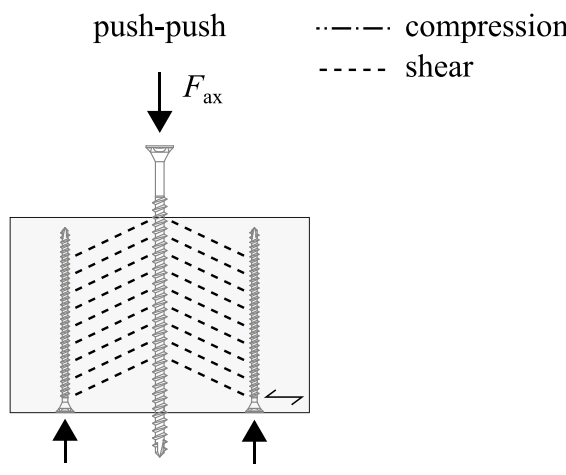

(d)

Fig. 1 Definition of compression and shear stresses according to Ringhofer and Schickhofer (2014b) 
In this study, a quasi-continuous fibre optic measurement technique with fibre Bragg gratings (FBGs) was developed for fully threaded self-tapping screws to investigate the force distribution along axially loaded screws in detail, with reference to the different test set-ups, as depicted in Fig. 1. Furthermore, the influence of the angle between the screw axis and the grain and the influence of material inhomogeneities such as density of the wood material were studied. Finally, the experimental results of the forces along the axially loaded screws under a screw to grain angle of $\Theta=0^{\circ}$ and $90^{\circ}$ were compared to results according to Volkersen's mechanical model (1953).

\section{Materials and methods}

\subsection{Self-tapping screw}

A commercial self-tapping screw according to ETA $-11 / 0190$ (ETA 2018a) was equipped as a measuring screw. The diameter was chosen to be $d=12 \mathrm{~mm}$ and the length of the screw was $l=440 \mathrm{~mm}$. The core diameter of the screw was $d_{\mathrm{c}}=7.1 \mathrm{~mm}$. The screw head was modified to a hexagonal head to enable the screw-in with the fibre coming out (Fig. 2a). The tensile capacity of the screw was determined experimentally as $R_{\mathrm{ax}} \approx 53 \mathrm{kN}$ with five preliminary tests. This corresponds to a tensile strength of $f_{\mathrm{u}}>1200 \mathrm{~N} / \mathrm{mm}^{2}$.

It was possible to drill a borehole utilising "fast hole drilling wire erosion" with a diameter of $d_{\mathrm{i}}=0.8 \mathrm{~mm}$ throughout the entire length of the screw. The optical fibre was glued-in using a special two-component epoxy designed for optical fibres (EPO-TEK 353ND). The borehole was cleaned, and the epoxy was pressed in until it leaked out at the screw tip. Subsequently, the fibre with the diameter of $d_{\mathrm{f}}=0.125 \mathrm{~mm}$ was inserted and the screw was stored for one hour under a temperature of $80^{\circ} \mathrm{C}$ (Fig. 2b).

\subsection{Optical fibre}

The FBGs reflect light of a specific wavelength. Nineteen FBGs were inscribed into the fibre core over a length of $360 \mathrm{~mm}$. The distance between each measuring point (FBG) was $a=20 \mathrm{~mm}$. The length of the single FBG was chosen as $l_{\mathrm{FBG}}=2.2 \mathrm{~mm}$.

A short wavelength infrared spectrum generated from an optical interrogator was introduced into the glass fibre. The optical spectrum of the FBG sensors was between $\lambda_{1}=1509 \mathrm{~nm}$ and $\lambda_{19}=1584 \mathrm{~nm}$. Each FBG reflected a specific wavelength with a peak $\lambda_{i}$ (see Fig. 2b). The peaks reflected were also detected by the optical interrogator. The elongation of the fibre also led to an elongation of the Bragg gratings, resulting in a shift of the peaks reflected in the optical spectrum. The shift of the peak was nearly linear to the elongation of the fibre. A strain of $1 \mu \mathrm{m} / \mathrm{m}$ corresponded approximately to the shift of the reflected wavelength of $1 \mathrm{pm}$.

The shift of the reflected wavelength was measured for each FBG in the tests. Thus, a calibration of each FBG was necessary before measuring axial forces along the screw axis. The calibration of the measurement screw was performed under constant tension over the entire measurement length of the screw (Fig. 2). The external force was applied stepwise until $F_{\text {ax }}=15 \mathrm{kN}$ which was limited by the embedding length of $33 \mathrm{~mm}$ of the screw in an aluminium bloc. Nevertheless, the relationship between the axial force in the single FBG $F_{\mathrm{i}}$ and the shift of the peak reflected $\lambda_{\mathrm{i}}$ was evaluated to be linear. Thus, a calibration factor $k_{\mathrm{i}}$ was detected for each FBG in the range of 6.1 to $7.1 \mathrm{~N} / \mathrm{pm}$. Furthermore, no defects due to air inclusions and the lack of fibre bonding were detected in the calibration process.

\subsection{Wood materials and specimens}

Specimens of GLT made from spruce (Picea abies) of the strength class GL 24h according to EN 14080 (2013) were used for the experimental tests. All samples were cut out of one beam. The density of the timber was measured close to the screw hole after testing under drying to $u=0 \%$ of the timber. The mean density was calculated as $\rho_{12 \%}=422 \mathrm{~kg} /$ $\mathrm{m}^{3}$ for a reference moisture content of $u=12 \%$ according to EN 384 (2019). The moisture of the GLT was measured as $u=8.1 \%$. The coefficient of variation (COV) was $5 \%$ for the density and $7 \%$ for the moisture for all specimens made of GLT. Additionally, specimens of laminated veneer lumber made of beech (LVL-B), according to ETA (2018b) were used for the pull-out tests. The mean density of the LVL-B specimens was calculated as $\rho_{12 \%}=835 \mathrm{~kg} / \mathrm{m}^{3}$ after drying to $u=0 \%$ and the moisture content was $u=5.4 \%$ according to EN 384 (2019).

The thickness was $t=120 \mathrm{~mm}$ and the width was $b=210 \mathrm{~mm}$ (see Fig. 3) for all specimens. The height of the timber parts was varied between $l=90$ and $360 \mathrm{~mm}$. Thus, the slenderness ratio between the diameter of the screw and the embedding length of $d / l$ was between 7.5 and 30 . The timber specimens were pre-drilled with a diameter of $8 \mathrm{~mm}$ to ensure a straight path of the screw axis and to reduce the torsion forces on the measurement screw during the screwin process.

Table 1 gives an overview of all specimens tested. The labelling displays the material in combination with the embedding length and the screw axis to grain angle. The 
Fig. 2 Design and detailing of the fibre Bragg grating measurement screw

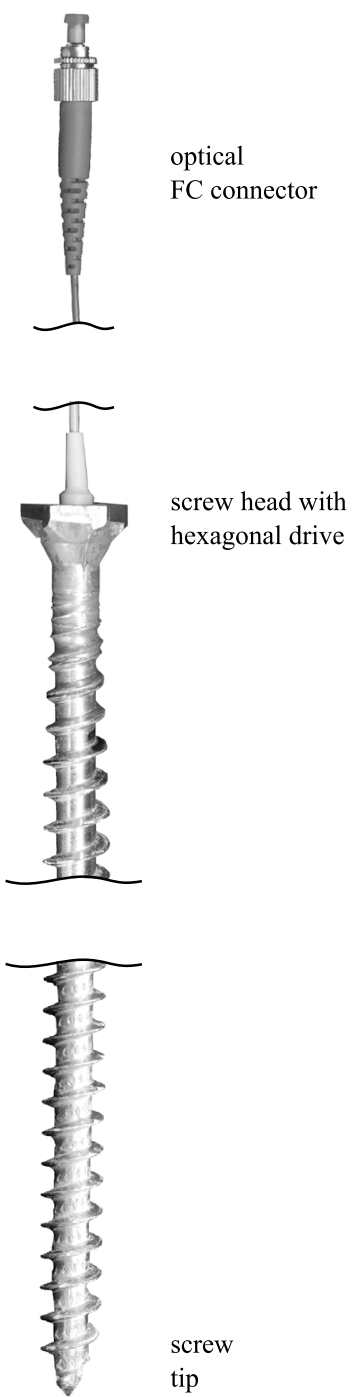

(a)

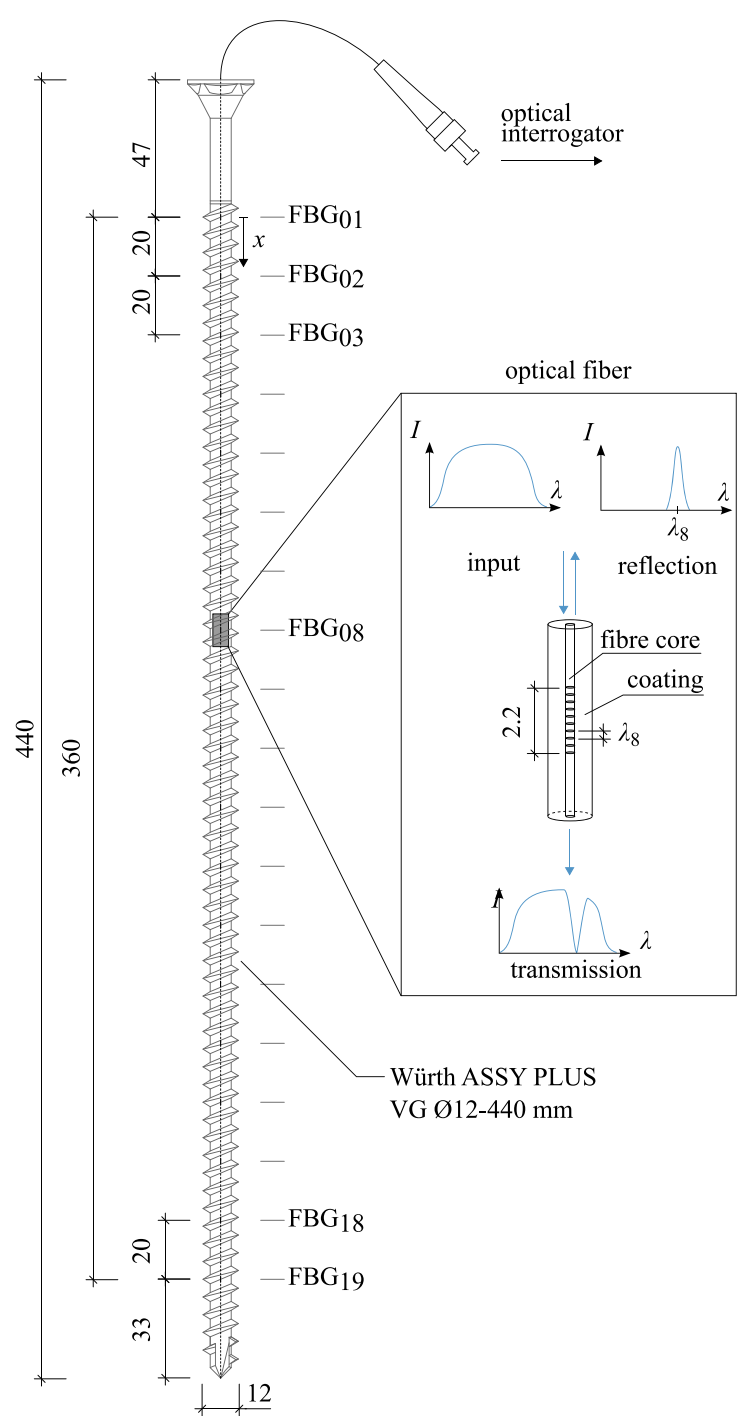

(b) angle was $\Theta=0^{\circ}, 30^{\circ}, 45^{\circ}, 60^{\circ}$ and $90^{\circ}$ for an embedding length of $l=270 \mathrm{~mm}$ and $\Theta=0^{\circ}$ resp. 90 for the other tests. The specimen LVLB90-GLT180-90 was a composite specimen of one section of LVL-B of $l=90 \mathrm{~mm}$ combined with one section of GLT of $l=180 \mathrm{~mm}$, which were glued together (Fig. 3b).

\subsection{Experimental programme and test set-up}

Overall, 28 tests were performed as a basis for a first experimental analysis. The load $F_{\text {ax }}$ was applied on the screw head controlled by the displacement $w$ under a constant velocity of $v=1.0 \mathrm{~mm} / \mathrm{min}$ using a Zwick and Roell testing machine. The load applied was increased constantly until $F_{\mathrm{ax}, \max } \approx 30 \mathrm{kN}$ and, subsequently, decreased at the same velocity back to zero. The total test time was around $600 \mathrm{~s}$. The maximum load was limited by the capacity of the screw reduced by a factor of 0.6 to avoid fatigue failure after all load cycles and under repeated screw in and screw out. Nevertheless, the design capacity of the screw against withdrawal failure was exceeded in the case of $l=90$ and $180 \mathrm{~mm}$. Withdrawal failure occurred before reaching $F_{\mathrm{ax} \text {,max }}$ only for specimen GLT90-00 and GLT90-90.

Four load configurations were investigated according to Fig. 1. Figure 3 depicts the pull-push/compression and pull-push/shear test set-up with the timber part fixed to the testing machine by a steel plate using four steel rods. The steel plate had a circular opening around the screw with a diameter of $72 \mathrm{~mm}(2 \cdot 3 d)$, 
Fig. 3 a Test set-up and dimensions for pull-push/shear load configuration and $\mathbf{b}$ specimen LVLB90-GLT180-90 under pull-push/compression loading

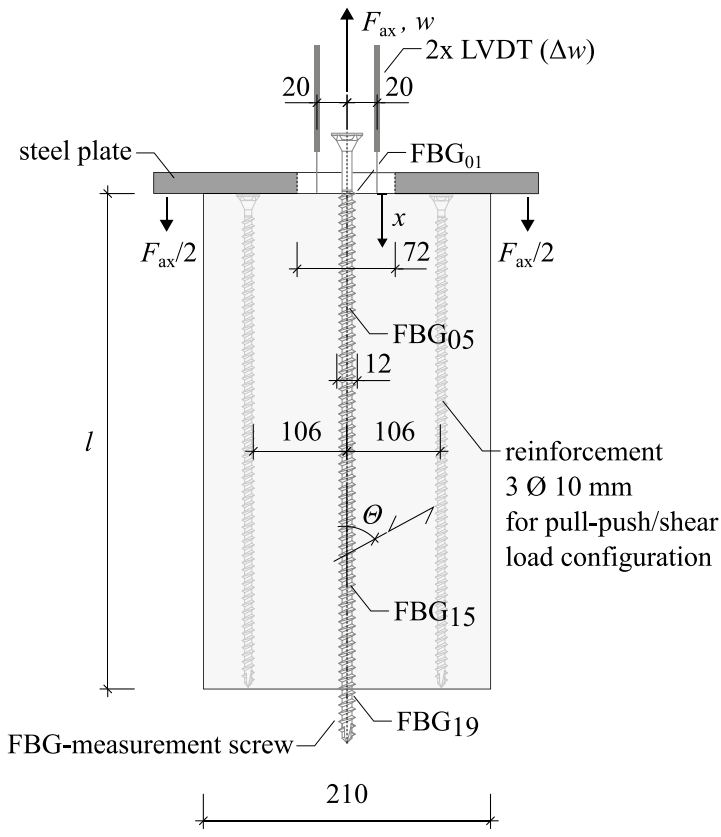

(a)

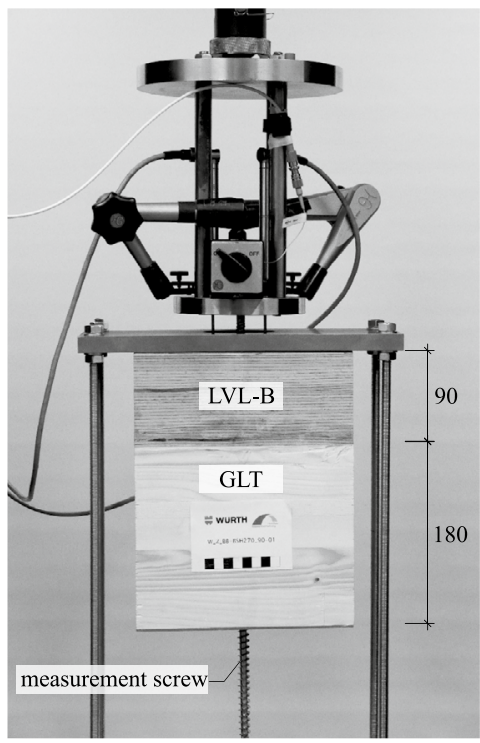

(b) following the considerations of Ringhofer and Schickhofer (2014b). The steel plate was arranged on the bottom side of the test specimen for the push-push/compression load configuration (Fig. 1b). In the push-push/ shear load configuration the supports were reinforced (Fig. 1d). The reinforcement with three fully threaded screws $(d=10 \mathrm{~mm})$ on each support was used to enable shear stresses inside the specimen under pull-push/
Table 1 Labelling and geometrical parameters of the specimens

\begin{tabular}{|c|c|c|c|c|c|}
\hline Specimen & Material & $\begin{array}{l}l \\
{[\mathrm{~mm}]}\end{array}$ & $\begin{array}{l}\Theta \\
{\left[{ }^{\circ}\right]}\end{array}$ & $n$ & Load configuration \\
\hline GLT90-00 & GLT & 90 & 0 & 1 & pull-push/compression \\
\hline GLT90-90 & GLT & 90 & 90 & 1 & pull-push/compression \\
\hline GLT180-00 & GLT & 180 & 0 & 1 & pull-push/compression \\
\hline GLT180-90 & GLT & 180 & 90 & 1 & pull-push/compression \\
\hline GLT270-00 & GLT & 270 & 0 & 5 & pull-push/compression \\
\hline GLT270-00-PUSH-C & GLT & 270 & 0 & 1 & push-push/compression \\
\hline GLT270-00-PULL-S & GLT & 270 & 0 & 1 & pull-push/shear \\
\hline GLT270-00-PUSH-S & GLT & 270 & 0 & 1 & push-push/shear \\
\hline GLT270-30 & GLT & 270 & 30 & 1 & pull-push/compression \\
\hline GLT270-45 & GLT & 270 & 45 & 1 & pull-push/compression \\
\hline GLT270-60 & GLT & 270 & 60 & 1 & pull-push/compression \\
\hline GLT270-90 & GLT & 270 & 90 & 5 & pull-push/compression \\
\hline GLT270-90-PUSH-C & GLT & 270 & 0 & 1 & push-push/compression \\
\hline GLT270-90-PULL-S & GLT & 270 & 0 & 1 & pull-push/shear \\
\hline GLT270-90-PUSH-S & GLT & 270 & 0 & 1 & push-push/shear \\
\hline GLT360-00 & GLT & 360 & 0 & 1 & pull-push/compression \\
\hline GLT360-90 & GLT & 360 & 90 & 1 & pull-push/compression \\
\hline LVLB90-GLT180-90 & LVL-B/GLT & 270 & 90 & 1 & pull-push/compression \\
\hline LVLB 270-00 & LVL-B & 270 & 0 & 1 & pull-push/compression \\
\hline LVLB 270-90 & LVL-B & 270 & 90 & 1 & pull-push/compression \\
\hline
\end{tabular}


shear and push-push/shear configurations. The heads of the reinforcement screws were in contact with the steel plates (Fig. 3a).

The test load $F_{\mathrm{ax}}$ and the axial forces in $19 \mathrm{FBGs} F_{\mathrm{FBG}, \mathrm{i}}$ were measured and stored at a frequency of $10 \mathrm{~Hz}$. Additionally, the deformation between the screw head $\Delta w$ and the timber surface was measured with two displacement transducers (LVDT).

\section{Experimental results}

\subsection{Sensitivity study}

In this part of the study the measurement screw was checked regarding the resolution of the optical sensor. Furthermore, the influence of the load level as well as the influence of the material inhomogeneities on the stresses along the screw axis was investigated.

Figure 4 depicts two possibilities to document the forces $F_{\text {FBG }}$ along the screw axis depending on the load $F_{\text {ax }}$ for a specimen made of GLT with $l=360 \mathrm{~mm}$ loaded perpendicular to the grain $\left(\Theta=90^{\circ}\right)$ as an example. Figure 4a shows the axial forces for 10 out of 19 measuring points. The first measuring point $\mathrm{FBG}_{01}$ close to the screw head nearly equals the load $F_{\text {ax }}$ applied. The axial forces in the embedded screw part vary depending on its position and the test load. The axial forces in the $\mathrm{FBG}_{01}, \mathrm{FBG}_{02}$ and $\mathrm{FBG}_{03}$ are significantly higher for a comparatively low level of loading $\left(F_{\mathrm{ax}}<7.5\right.$ $\mathrm{kN})$ compared to the FBGs behind. With increasing load, the difference between the forces in each FBG became more balanced.

An alternative representation is displayed in Fig. 4b, where the local forces $F_{\mathrm{FBG}}$ are related to the loading $F_{\mathrm{ax}}$.
The results start with $F_{\mathrm{ax}} \geq 1 \mathrm{kN}$ due to the resolution of the measuring system. The share of the loading for the $\mathrm{FBG}_{01}$ starts at 0.9 and increases to about 0.98 for $F_{\text {ax }}>10 \mathrm{kN}$. The difference between the load applied and the force measured in the first FBG could be explained by small eccentricities at the screw head where the load is introduced.

All the measuring points show a maximum of the related axial force between a load level of 10 and $20 \mathrm{kN}$. The share decreases again after the local maximum is reached. The difference between the individual loads referred to the axial loads $F_{\mathrm{FBG}} / F_{\text {ax }}$ is more balanced for a test load of about 30 $\mathrm{kN}$ compared to smaller load levels. An explanation might be local defects in the upper part of the embedding length which leads more and more to a force shifting along the screw axis.

Even without any withdrawal failure, the axial forces along the screw axis showed a nonlinear distribution. A transfer of the axial forces between the measuring points is visible with an increasing load level.

The sensitivity study documented the influence of the load level on the development of axial forces along the screw axis. For a better overview, the axial force along the screw will be evaluated for $F_{\mathrm{ax}}=9 \mathrm{kN}$ and $F_{\mathrm{ax}, \max } \approx 30 \mathrm{kN}$ in the following analysis.

Overall, 22 tests were performed in a pull-push/compression configuration (see Fig. 3b) to study the influence of the embedding length and the screw axis to grain angle $\Theta$ on the force distribution along the screw axis. Figure 5 shows the axial forces $F_{\mathrm{FBG}}$ in each FBG along the screw axis $x$ for different levels of the load $F_{\mathrm{ax}}$ applied for two specimens each with $l=360 \mathrm{~mm}$. The timber specimen made of GLT in Fig. 5a was loaded parallel to the grain $\left(\Theta=0^{\circ}\right)$. The axial force decreased to zero within the first $100 \mathrm{~mm}$ for the first loading steps up to $F_{\mathrm{ax}}=3 \mathrm{kN}$. It is obvious that the axial forces decrease to $15 \mathrm{kN}$ within the first $120 \mathrm{~mm}$ of the
Fig. 4 Specimen GLT360-90: a local forces $\mathrm{F}_{\mathrm{FBG}}$ depending on the test load $\mathrm{F}_{\mathrm{ax}}$ and $\mathbf{b}$ local forces $\mathrm{F}_{\mathrm{FBG}}$ related to $\mathrm{F}_{\mathrm{ax}}$

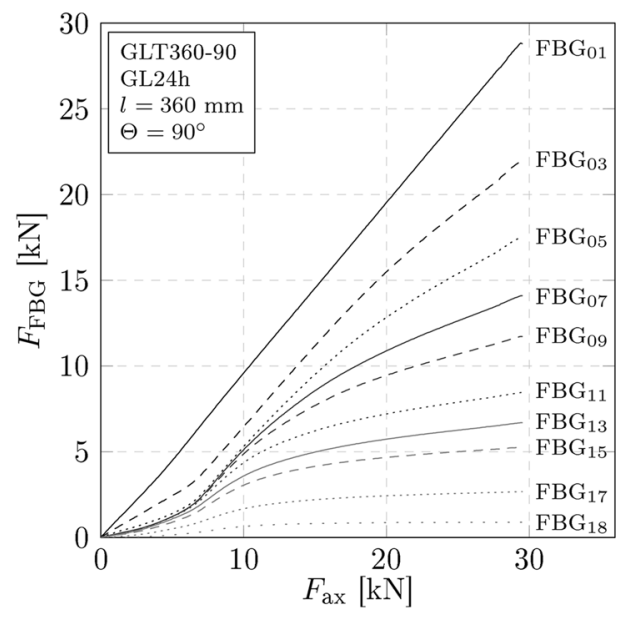

(a)

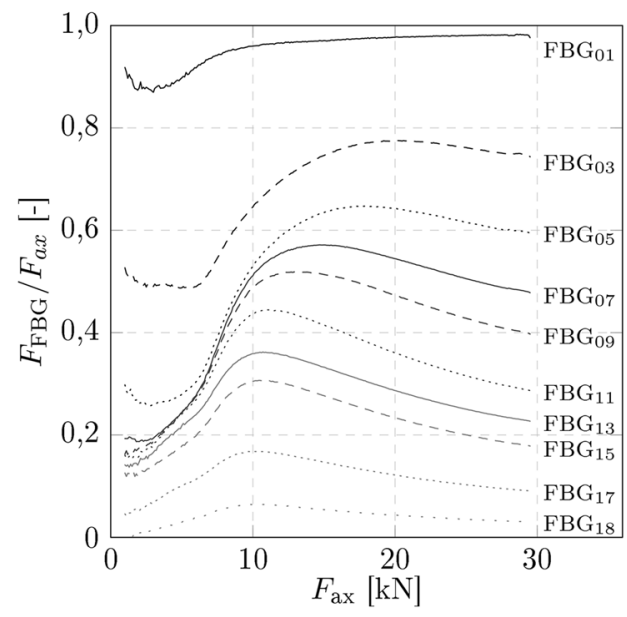

(b) 
screw thread for a load level of $F_{\text {ax }} \approx 30 \mathrm{kN}$. No significant change in the axial forces is visible in the middle of the screw between $x=160$ and $260 \mathrm{~mm}$. The axial forces for the section $x>260 \mathrm{~mm}$ decrease rapidly to zero until $x=l$.

Figure $5 \mathrm{~b}$ depicts the axial forces if the screw is oriented perpendicular to the grain. The distribution of axial forces is similar to the situation when the screw is oriented parallel to the grain until a load of $9 \mathrm{kN}$ is applied. With increasing load, the decrease in the axial force in the first FBGs becomes more linear but still with a relatively high reduction in axial forces within the first $40 \mathrm{~mm}$.

Figure 6a shows the mean values of axial forces of five tests carried out with an embedding length of $l=270 \mathrm{~mm}$ and the screw axis to grain directions of $\Theta=0^{\circ}$ and $90^{\circ}$ for $F_{\text {ax }}=29.5 \mathrm{kN}$. For $\Theta=0^{\circ}$ a more convex and for $\Theta=90^{\circ} \mathrm{a}$ more concave distribution is visible. The scattering of the experimental results varies along the screw axis but does not influence the overall distribution of axial forces along the screw significantly.

Additionally, the minimum and maximum values out of the five tests are displayed.

The difference of the axial force between two measurement points could be defined as the bond force $\Delta F_{\mathrm{FBG}}$.

$\Delta F_{F B G, i}=F_{F B G, i+1}-F_{F B G, i}$

The bond force will be transferred from the screw thread to the timber between two measurement points. With reference to the cylindrical shell surface area of the screw, the corresponding bond stresses $f_{\mathrm{b}}$ could be determined as well.

The bond forces $\Delta F_{\mathrm{FBG}}$ for configuration GLT270-00 and GLT270-90 are shown in Fig. 6b. The maximum bond force at a load level of $F_{\mathrm{ax}}=29.5 \mathrm{kN}$ is around $4.0 \mathrm{kN}$. Two local maximums of $\Delta F_{\mathrm{FBG}}$ at $\mathrm{x}=80 \mathrm{~mm}(x / l=0.35)$ and $\mathrm{x}=220 \mathrm{~mm}(x / l=0.85)$ occur if the screw axis is parallel to the grain (GLT270-00). Regarding a screw axis perpendicular to the grain $\Theta=90^{\circ}$ (GLT270-90), the maximum bond force is located at $x=20 \mathrm{~mm}(x / l=0.1)$. A second local maximum is located at $x=180 \mathrm{~mm}(x / l=0.7)$.
The difference in maximum and minimum values of specific measuring points varies along the screw axis between 0.5 and $3.0 \mathrm{kN}$ (see Fig. 6b). Regarding the test series GLT270-00, the range of test results is comparatively small within the first $80 \mathrm{~mm}$ of the embedding length and increases with higher mean values of the bond force. Regarding a screw axis to grain angle of $\Theta=90^{\circ}$, the range decreases along the embedding length, except for $x=20$ to $40 \mathrm{~mm}$.

The difference in the position of the first local maximum of the bond forces for different screw to grain angles can be explained by compression stresses to the supports, according to Fig. 7a, b. Following the investigations of Bernasconi (1996), the load distribution angle is roughly $\alpha=15^{\circ}$ for screws oriented parallel to the grain and about $\alpha=60^{\circ}$ if oriented perpendicular to the grain. Thus, different positions of the first local maximums under different screw axis to grain angles are to be expected.

The second local maximum can be explained by the test set-up. Regarding a pull-push configuration, tension forces $F_{\mathrm{t}}$ and compression forces $F_{\mathrm{c}}$, both perpendicular to the screw axis, appear (Fig. 7c). $F_{\mathrm{t}}$ is located close to the screw head in the timber specimen and $F_{\mathrm{c}}$ at the bottom side of the specimen. The compression stresses due to $F_{\mathrm{c}}$ might enhance the bonding behaviour and increase the bond forces.

In the subsequent sections the following parameters will be studied: The bond forces $\Delta F_{\mathrm{FBG}}$ for different load configurations, embedding lengths, screw axis to grain angles and inhomogeneity of density.

\subsection{Influence of support conditions}

The test set-up as depicted in Fig. 3 was modified to investigate three more support conditions according to Fig. 1. Test specimens GLT270-00-PUSH-C and GLT270-90-PUSH$\mathrm{C}$ were loaded under compression of the screw head. Figures $8 \mathrm{a}, \mathrm{b}$ show the bond forces for the two load levels of $F_{\text {ax }}=9 \mathrm{kN}$ (dark grey) and $F_{\text {ax }} \approx 30 \mathrm{kN}$ (grey). The maximum bond forces for both screw axis to grain angles develop
Fig. 5 Pull-out tests on GL24h with $1=360 \mathrm{~mm}$. Development of axial forces for screw axis a parallel to the grain and $\mathbf{b}$ perpendicular to the grain

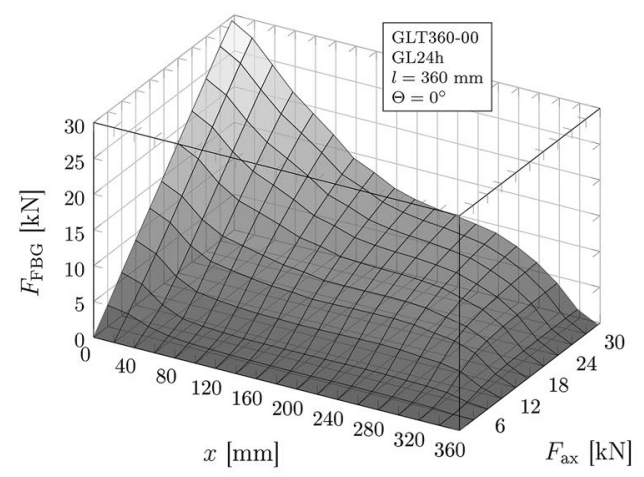

(a)

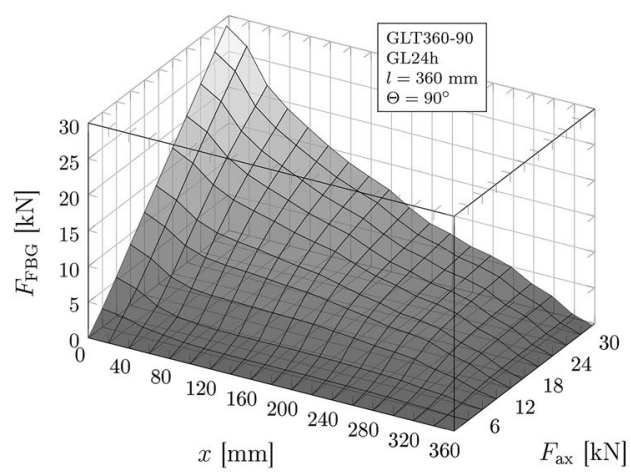

(b) 
Fig. 6 Mean values of a the axial force $\mathrm{F}_{\mathrm{FBG}}$ along the screw axis for $\Theta=0^{\circ}$ and $90^{\circ}$ and $\mathbf{b}$ bond forces $\Delta \mathrm{F}_{\mathrm{FBG}}$ for an embedding length of $1=270 \mathrm{~mm}$ out of five tests each

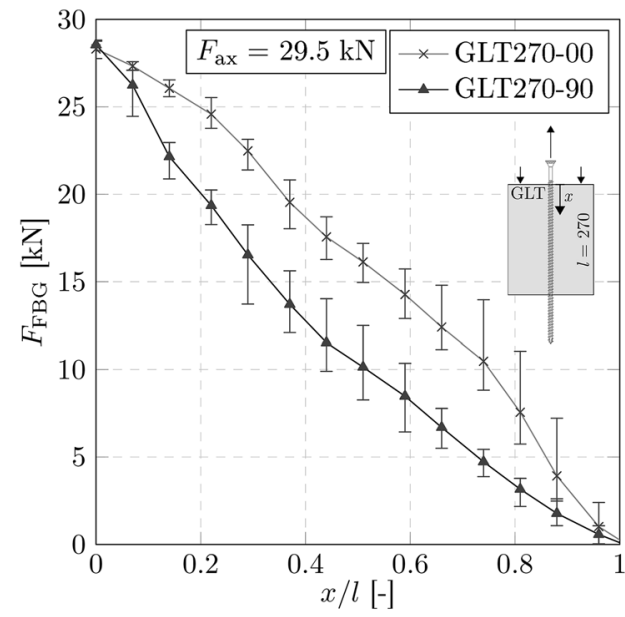

(a)

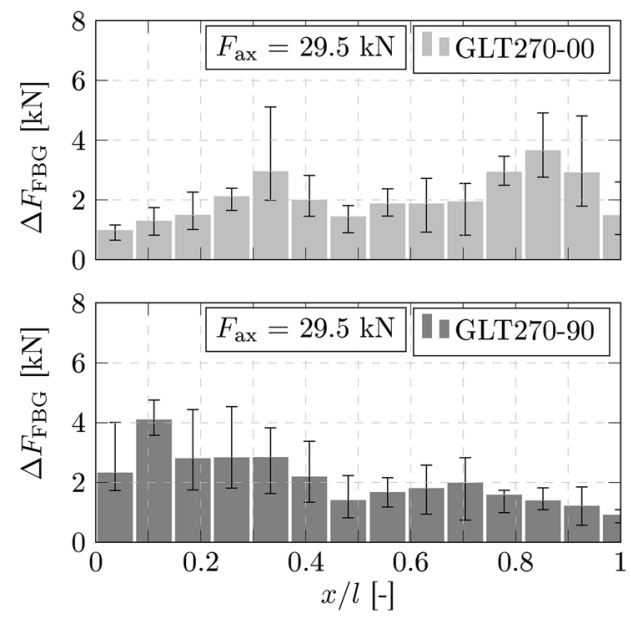

(b) in the first $90 \mathrm{~mm}$. Hardly any forces are transferred in the section for $\mathrm{x}>100 \mathrm{~mm}$ for a load of $9 \mathrm{kN}$. Regarding the load of $F_{\text {ax }} \approx 30 \mathrm{kN}$, the maximum bond force increases to about $8 \mathrm{kN}$ if the screw is in a parallel direction to the grain and up to $10 \mathrm{kN}$ if the screw is oriented perpendicular to the grain. Taking into account a bond surface of $A_{b}=\pi \bullet 12 \mathrm{~mm}$ - $20 \mathrm{~mm}=754 \mathrm{~mm}^{2}$ between each FBG, the maximal bond stresses rise to $f_{\mathrm{b}}>10 \mathrm{~N} / \mathrm{mm}^{2}$.

Four tests were carried out with reinforced supports considering pull-push/shear and push-push/shear load configurations. Figure $8 \mathrm{c}$ shows the bond forces of the pull-push/ shear tests of specimen GLT270-00-PULL-S. The bond forces for both levels of the load applied are more constant along the screw axis compared to the push compression tests with a maximum of bond forces between $x=40$ and $80 \mathrm{~mm}$. Under a screw axis to grain angle of $\Theta=90^{\circ}$
(GLT270-90-PULL-S), the bond forces are nearly constant along the embedding length for both load levels (Fig. 8d).

Figures $8 \mathrm{e}, \mathrm{f}$ show the bond forces along the screw axis of a push-push/shear load configuration with reinforced supports. If the screw is oriented parallel to the grain (GLT27000-PUSH-S), local maximums of bond forces are visible for $\mathrm{x}=40 \mathrm{~mm}$ and $\mathrm{x}=260 \mathrm{~mm}$. Compared to the results of the specimen GLT270-00-PUSH-C, no outstanding peak of bond forces was detected under an applied load of $F_{\mathrm{ax}} \approx$ $30 \mathrm{kN}$. If the screw was oriented perpendicular to the grain (GLT270-90-PUSH-S), most of the forces were transmitted within the first section of the embedding length for an applied load of $9 \mathrm{kN}$. Regarding an applied load of $30 \mathrm{kN}$, more than 85 percent of the axial forces were transmitted within the first $160 \mathrm{~mm}$ of the screw thread.

Under a push-push load configuration (GLT27000-PUSH-C and GLT270-00-PUSH-S), the maximum of
Fig. 7 Compression stresses between the screw shaft and the support for a screw to grain angle of $\Theta=90^{\circ}$ and $\mathbf{b} \Theta=0^{\circ}$ as well as $\mathbf{c}$ the equilibrium of forces of the half specimen

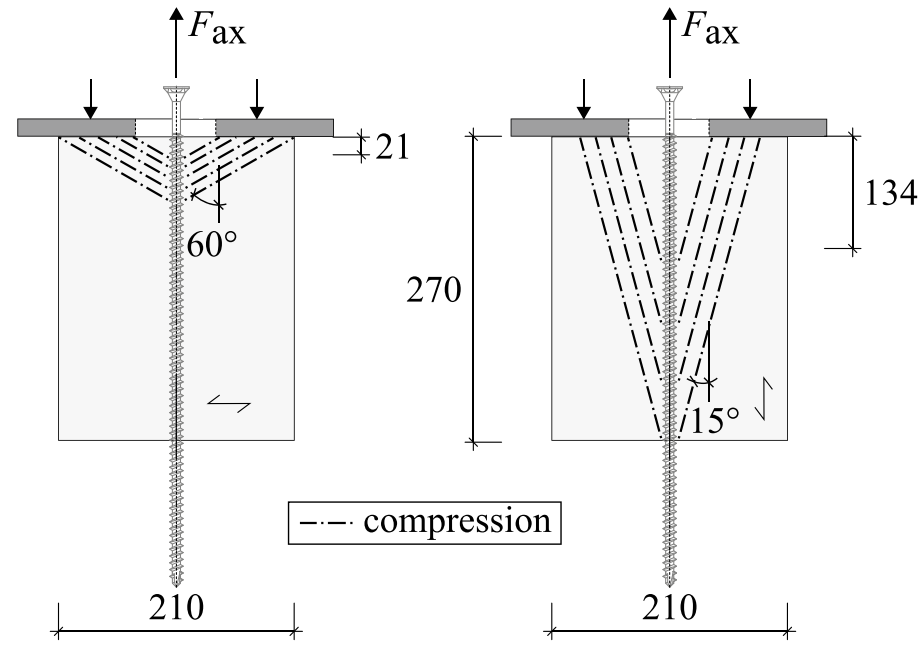

(a) (b)

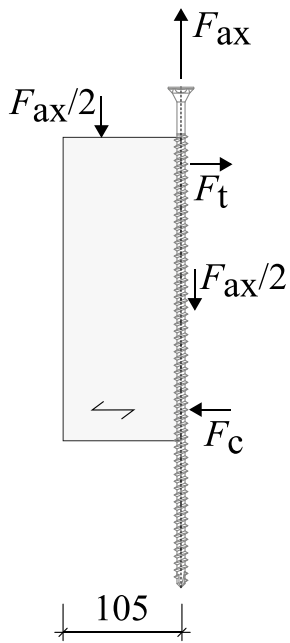

(c) 
bond forces shifts with increasing load from $\mathrm{x}=40 \mathrm{~mm}$ to $\mathrm{x}=90 \mathrm{~mm}$ if the screw axis is parallel to the grain. In both configurations, the load slip behaviour shows a nonlinear characteristic. Together with the shift of the maximum bond forces, initiating withdrawal respectively buckling failure was visualised in this study along the embedded screw.

The experimental results of different support conditions show significant differences in the force distribution of axially loaded screws. Outstanding bond force peaks over $8 \mathrm{kN}$ could be attributed to local compression stresses in the interface to the surrounding timber. Thus, the results will support the idea of a load distribution according to Ringhofer and Schickhofer (2014b).

However, these findings support the idea that different distributions of stresses such as shear and compressive stresses in the interface of the screw are possible. The knowledge of the distribution of stresses around the screw could help to improve the design of reinforcements in case of notches or holes in beams. Furthermore, the force distribution might be considered in the design of screws arranged in groups or for the spacings between the screw to optimize the load bearing capacity of connections. For upcoming experimental investigations, these findings of the force distribution should be recognized concerning the activated timber volume around the screws, especially for screw to grain angles of $\Theta=0^{\circ}$.

\subsection{Influence of embedding length}

The length of the timber specimen was varied between 90 , 180 and $360 \mathrm{~mm}$ with screw axis to grain angles of $\Theta=0^{\circ}$ and $90^{\circ}$ to study the influence of the embedding length. The corresponding slenderness was between $1 / \mathrm{d}=7.5$ and 30 . Figure 9 shows the results for the load levels of $F_{\mathrm{ax}}=9 \mathrm{kN}$ (dark grey) and $F_{\mathrm{ax}} \approx 30 \mathrm{kN}$ (grey) applied.

The maximum pull-out force for the specimen GLT9000 was $F_{\mathrm{ax}}=14.5 \mathrm{kN}$, resulting in withdrawal failure of the screw (Fig. 9a). Under the failure load, the maximum bond force was $\Delta F_{\mathrm{FBG}} \approx 3.5 \mathrm{kN}$ along the screw axis. The distribution of bond forces for a screw axis to grain angle (GLT90-90) was similar for both load levels (Fig. 9b). Under a pull-out force of $30 \mathrm{kN}$, the maximum bond force was $\Delta F_{\mathrm{FBG}} \approx 8 \mathrm{kN}$.

Figures $9 \mathrm{c}, \mathrm{d}$ show the force distribution for an embedding length of $l=180 \mathrm{~mm}$. Specimen GLT180-00 with a screw axis to grain angle of $\Theta=0^{\circ}$ showed higher bond forces at the end of the embedded part of the screw. The bond force for screws perpendicular to the grain is almost constant along the screw axis for $F_{\mathrm{ax}}=9 \mathrm{kN}$. The bond forces increase up to $\Delta F_{\mathrm{FBG}}=4 \mathrm{kN}$ without significant peaks.

If the embedding length of the screw is $l=360 \mathrm{~mm}$, bond forces exhibit two peaks, one at the beginning for $x=20-40 \mathrm{~mm}$ and the other close to the end of the screw. This does not seem to depend on the screw axis to grain angle.
Fig. 8 Bond forces under different support conditions according to Fig. 1 for load levels of $\mathrm{F}_{\mathrm{ax}}=9 \mathrm{kN}$ (dark grey) and $\mathrm{F}_{\mathrm{ax}} \approx$ $30 \mathrm{kN}$ (grey)

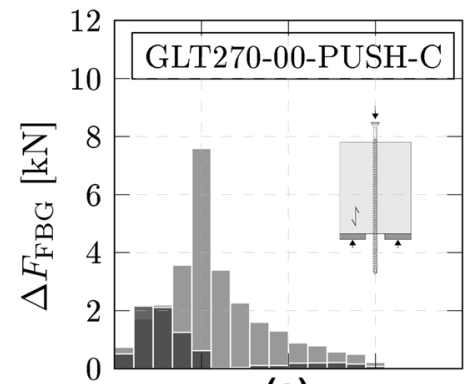

(a)

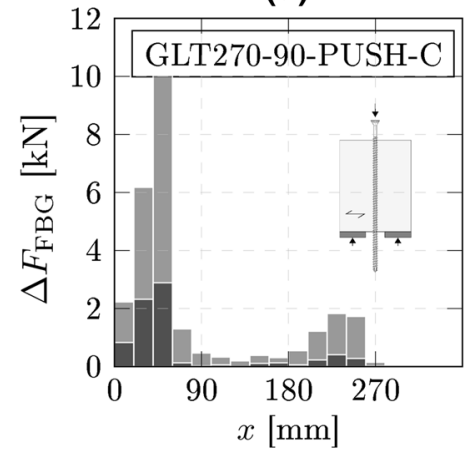

(b)

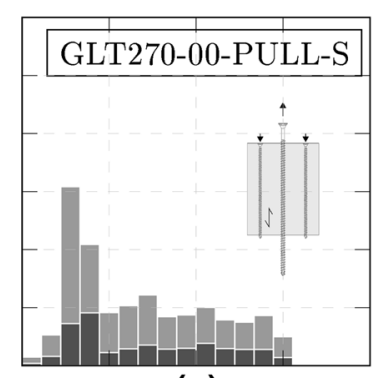

(c)

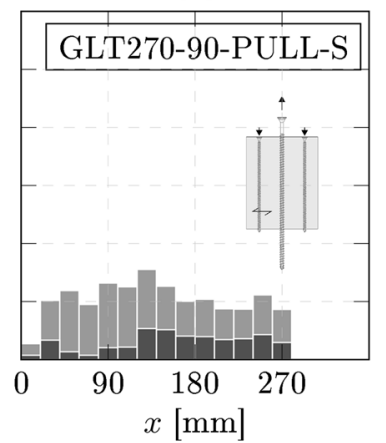

(d)

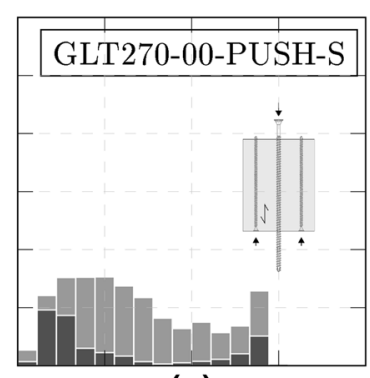

(e)

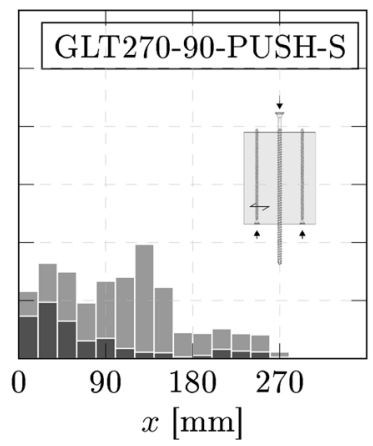

(f) 
The experimental results demonstrate that the force distribution depends on the embedding length of a fully threaded screw. In some cases, more than one maximum of bond forces could be identified along the screw length. Thus, secondary effects caused by the test set-up seem to have an influence on the load distribution of self-tapping screws.

\subsection{Influence of the screw axis to grain angle}

It has already been well documented that the screw axis to grain angle of $\Theta=0^{\circ}$ and $90^{\circ}$ leads to different positions of local maximums of the bond forces. Additional tests were carried out to cover the range between $0^{\circ}$ and $90^{\circ}$. For a load of $F_{\text {ax }}=30 \mathrm{kN}$ and a screw axis to grain angle of $\Theta=30^{\circ}$, most of the axial forces were transferred between $140 \mathrm{~mm}<\mathrm{x}<260 \mathrm{~mm}$. This is comparable to a screw axis to grain angle of $\Theta=0^{\circ}$. For a screw axis to grain angle of $\Theta=45^{\circ}$ and $60^{\circ}$, the bond forces occur mainly between $0 \mathrm{~mm}<\mathrm{x}<160 \mathrm{~mm}$. This behaviour was already discovered for $\Theta=90^{\circ}$.

If the screw with $l_{\mathrm{ef}}=270 \mathrm{~mm}$ is inclined in between $\Theta=30^{\circ}, 45^{\circ}$ and $60^{\circ}$, only one local maximum of bond force is obvious for $x / l \approx 0.5$ for both load levels of $F_{\mathrm{ax}}=9$ $\mathrm{kN}$ and $30 \mathrm{kN}$ (Fig. 10). The maximum bond force $\Delta F_{\mathrm{FBG}}$ increases to $4 \mathrm{kN}$ for the specimen GLT270-45 and to $6 \mathrm{kN}$ for specimens GLT270-30 and GLT270-60.

\subsection{Impact of material and density}

The final test series was performed to investigate the influence of higher and graduated density on the force distribution. Regarding specimen LVLB270-00, the screw was driven parallel to the grain into LVL-B. A major share of bond forces develops within the first $60 \mathrm{~mm}$ for a load level of $F_{\mathrm{ax}}=9 \mathrm{kN}$ (Fig. 11a). The increase in load applied to $F_{\mathrm{ax}}$ $\approx 30 \mathrm{kN}$ results in a levelling of bond forces, with one peak close to the screw head. Specimen LVLB270-90 showed a similar behaviour with few higher bond forces within the first $60 \mathrm{~mm}$ (Fig. 11b).

Test specimen LVLB90-GLT180-90 is a combination of $90 \mathrm{~mm}$ LVL-B and $180 \mathrm{~mm}$ GLT which had been glued together (see Fig. 3b). Thus, the embedding length was $l=270 \mathrm{~mm}$ in total and the screw axis to grain angle was $\Theta=90^{\circ}$. Due to the higher density of LVL-B compared to GLT, more than 60 percent of the axial forces were transmitted within the LVL-B in the first $90 \mathrm{~mm}$ (Fig. 11c). Only minor bond forces were determined in the interface of the screw and the GLT part.

The results confirm that the density has a significant impact on the force distribution of self-tapping screws. On the one hand, the more homogeneous LVL-B shows a more constant bonding behaviour. On the other hand, the higher density and stiffness result in higher bond forces within the
Fig. 9 Bond forces under different embedding length for an applied load of $\mathrm{F}_{\mathrm{ax}}=9 \mathrm{kN}$ (dark grey), $\mathrm{F}_{\mathrm{ax}}=14.5 \mathrm{kN}$ (light grey) and $\mathrm{F}_{\mathrm{ax}} \approx 30 \mathrm{kN}$ (grey)

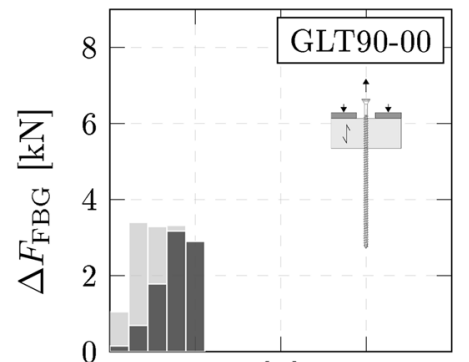

(a)

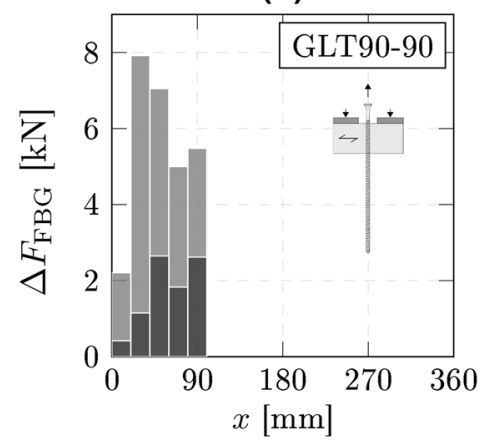

(b)

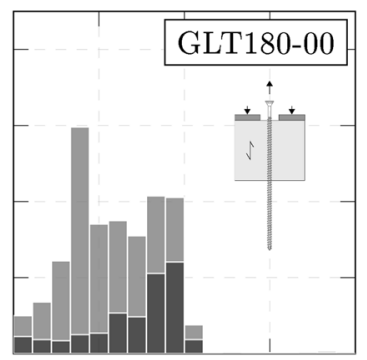

(c)

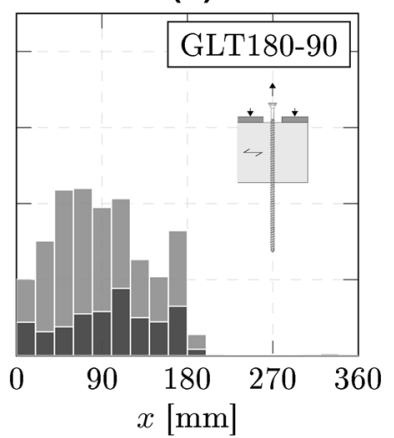

(d)

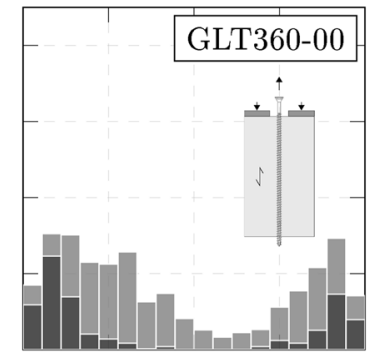

(e)

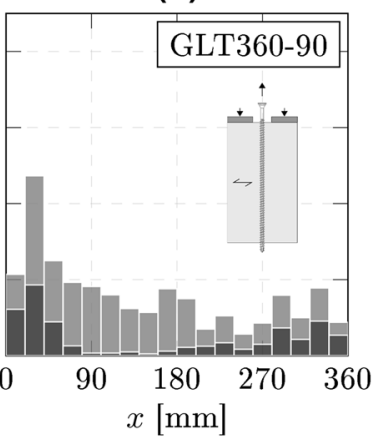

(f) 
first $60 \mathrm{~mm}$. In particular, the MOE perpendicular to the grain of LVL-B is more than double of GL24h. Thus, compression stresses to the supports could have more influence compared to the specimens made of GL $24 \mathrm{~h}$. The higher density also leads to a concentration of bond forces within the LVL-B part of a composite body.

\section{Mechanical model}

\subsection{Volkersen's shear-lag theory}

Pörtner (2006) used a set of differential equations to qualify interface shear stresses in the bond line between glued-in rods and the surrounding wood. This mechanical approach was originally proposed by Volkersen (1953). Subsequently, the equation was adopted by Ringhofer and Schickhofer (2014a) for the verification of experimental tests on the bond behaviour of self-tapping screws. They defined the axial force $N_{\mathrm{ax}}$ along the screw as

$N_{a x}=F_{a x} \cdot \frac{\sinh (\omega \cdot x)}{\sinh \left(\omega \cdot l_{e f}\right)}$, with $\omega=\frac{G}{t} \cdot \pi \cdot d_{c} \cdot\left(\frac{1}{(E A)_{s t}}+\frac{1}{(E A)_{w}}\right)$,

where $F_{\text {ax }}$ is the load applied on the screw head and $x$ the position along the embedding length $l_{\mathrm{ef}}$. $G$ is the shear modulus and $t$ the thickness of the shear stressed layer. The core diameter of the screw is defined by $d_{\mathrm{c}}$ and the axial rigidity is $(E A)_{\mathrm{st}}$ for the steel. The rigidity $(E A)_{\mathrm{w}}$ of the surrounding wood was defined depending on the screw axis to grain angle. This model is valid for pull-push/compression specimens only and does not take into account any bilinear softening behaviour, which was considered by Pörtner (2006).

Ringhofer and Schickhofer (2014a) verified the test results for self-tapping screws with a diameter of $d=12 \mathrm{~mm}$ with geometrical model parameters, as shown in Fig. 12. Two different assumptions for the effective timber volume were made. A first approach was the definition of an elliptical area $A_{\mathrm{w}, 1}$ with the radius $b_{\mathrm{w}, 1}$ and $a_{\mathrm{w}, 1}$ for a screw axis to grain angle of $\Theta=90^{\circ}$ and a circular area with $a_{\mathrm{w}, 1}=b_{\mathrm{w}, 1}$ for
$\Theta=0^{\circ}$. As a second approach, the entire cross-section with $A_{\mathrm{w}, 2}$ for both screw axis to grain orientations was considered as an effective volume (see Fig. 12). The authors defined the shear stressed area $A_{\mathrm{sh}}$ to be circular for $\Theta=0^{\circ}$ and $\Theta=90^{\circ}$ with $\mathrm{t}=14.5 \mathrm{~mm}$, respectively, $\mathrm{t}=22.0 \mathrm{~mm}$. For a screw axis to grain angle of $\Theta=90^{\circ}$ the shear modulus $G_{\mathrm{TR}}$ and the elastic modulus $E_{90}$ and for $\Theta=0^{\circ}$ the shear modulus $G_{\mathrm{LT}}$, respectively, $G_{\mathrm{LR}}$ and the elastic modulus $E_{0}$ will be decisive.

\subsection{Experimental validation of the model}

Volkersen's mechanical model was validated against the experimental results of the test series GLT270-00 and GLT270-90 with five tests each. The shear-stressed area $A_{\text {sh }}$ was chosen with the radius $t=14.5 \mathrm{~mm}$ for $\Theta=0^{\circ}$ and $t=22.0 \mathrm{~mm}$ for $\Theta=90^{\circ}$, according to the assumption of Ringhofer and Schickhofer (2014a). Geometrical and mechanical parameters are summarized in Table 2. The shear modulus $G_{\mathrm{LT}}$ was set to $650 \mathrm{~N} / \mathrm{mm}^{2}$ for parallel shear, according to EN 14080 (2013). If the screw to grain angle is $\Theta=90^{\circ}$, the shear plane in the radial-tangential plane $G_{\mathrm{RT}}$ is estimated at $40 \mathrm{~N} / \mathrm{mm}^{2}$. Regarding the verification, the area $\mathrm{A}_{\mathrm{w}, 1}$ was assumed to be circular with $a_{\mathrm{w}, 1}=b_{\mathrm{w}, 1}=36 \mathrm{~mm}$ for both test series because of the round opening in the support plate around the screw axis with the diameter $d=72 \mathrm{~mm}$. The modulus of elasticity in the direction of the screw axis was $E_{\mathrm{w}}=11,500 \mathrm{~N} / \mathrm{mm}^{2}$ for $\Theta=0^{\circ}$ and $E_{\mathrm{w}}=300 \mathrm{~N} / \mathrm{mm}^{2}$ for $\Theta=90^{\circ}$, according to EN 14080 (2013). The core diameter of the screw was $d_{\mathrm{c}}=7.1 \mathrm{~mm}$ and its modulus of elasticity was chosen according to ETA-11/0190 (2018a).

Figures 13a, b compare the axial forces along the screw axis for a load level of $F_{\mathrm{ax}}=29.5 \mathrm{kN}$, as calculated with the mechanical model regarding the experimental results. A good accordance between the forces calculated and the test results is detected for test series GLT270-90. Both force distributions show a slightly concave shape. While the development of axial forces changes from a slightly concave to a slightly convex shape for test series GLT270-00 in the
Fig. 10 Bond forces for different screw axis to grain angles for an applied load of $\mathrm{F}_{\mathrm{ax}}=9$ $\mathrm{kN}$ (dark grey) and $\mathrm{F}_{\mathrm{ax}} \approx 30 \mathrm{kN}$ (grey)

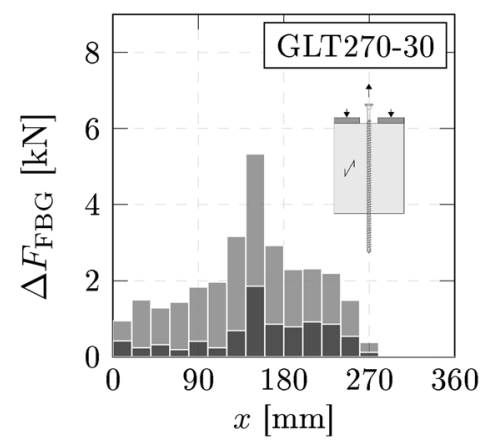

(a)

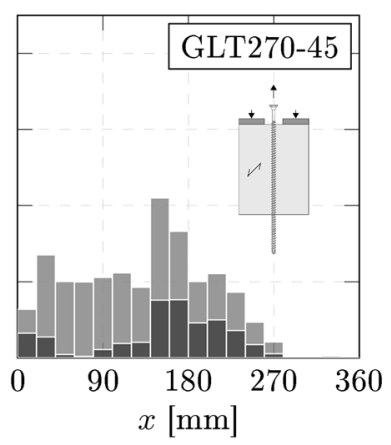

(b)

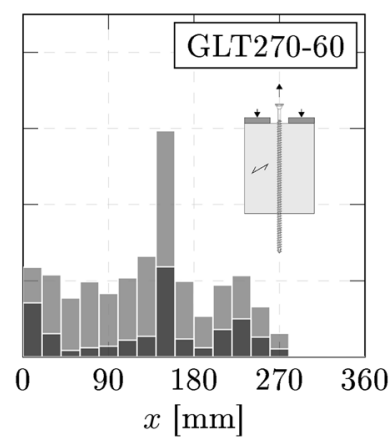

(c) 
Fig. 11 Bond forces of the specimens made of beech laminated veneer timber for a screw axis parallel to the grain and $\mathbf{b}$ perpendicular to the grain and $\mathbf{c}$ a combination with GLT for an applied load of $\mathrm{F}_{\mathrm{ax}}=9 \mathrm{kN}$ (dark grey) and $\mathrm{F}_{\mathrm{ax}} \approx 30 \mathrm{kN}$ (grey)

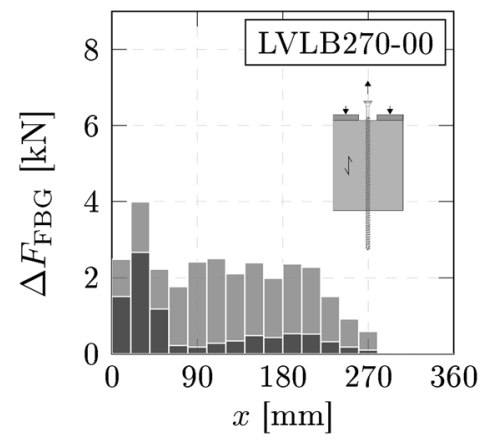

(a)

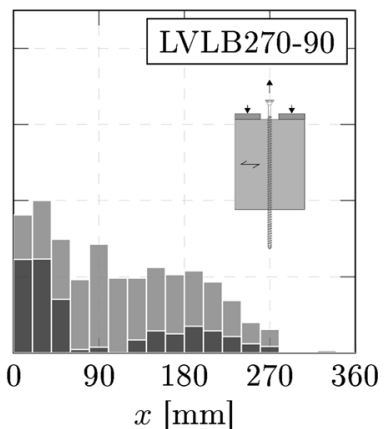

(b)

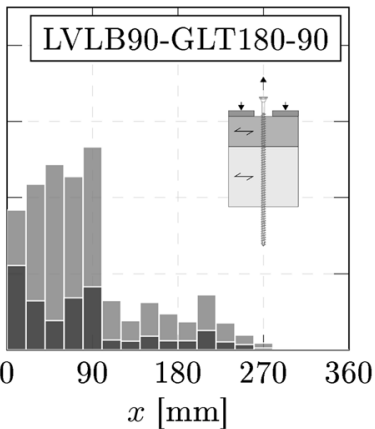

(c) tests, the calculation results provide an even more concave development.

The bond forces calculated along the screw axis are compared to the test results in Fig. 13c, d. The mechanical model shows a maximum at the beginning of the embedding length of the screw for both situations. The decrease in bond forces as derived from test results is generally not constant along the screw axis. If the screw axis is parallel to the grain, the maximum bond force of $\Delta F \approx 6 \mathrm{kN}$ decreases rapidly within the first $100 \mathrm{~mm}$ of the embedding length. When the screw axis is oriented perpendicular to the grain, the bond force shows a more or less linear distribution along the embedding length. The maximum bond force is then $\Delta F \approx 4 \mathrm{kN}$.
However, the two local maximums in the distribution of the bond forces resulting from compression stresses could not be represented by the mechanical model, assuming linear-elastic bond behaviour under shear stresses. According to the investigations of Pörtner (2006), the consideration of nonlinear softening should help to improve the model towards the description of a first local maximum.

\section{Conclusion and outlook}

The development and application of a measurement screw equipped with fibre optic sensors was presented. The screw enables the determination of axial forces along the screw
Fig. 12 Specifications of the geometrical parameters used for the mechanical model according to Ringhofer and Schickhofer (2014a)
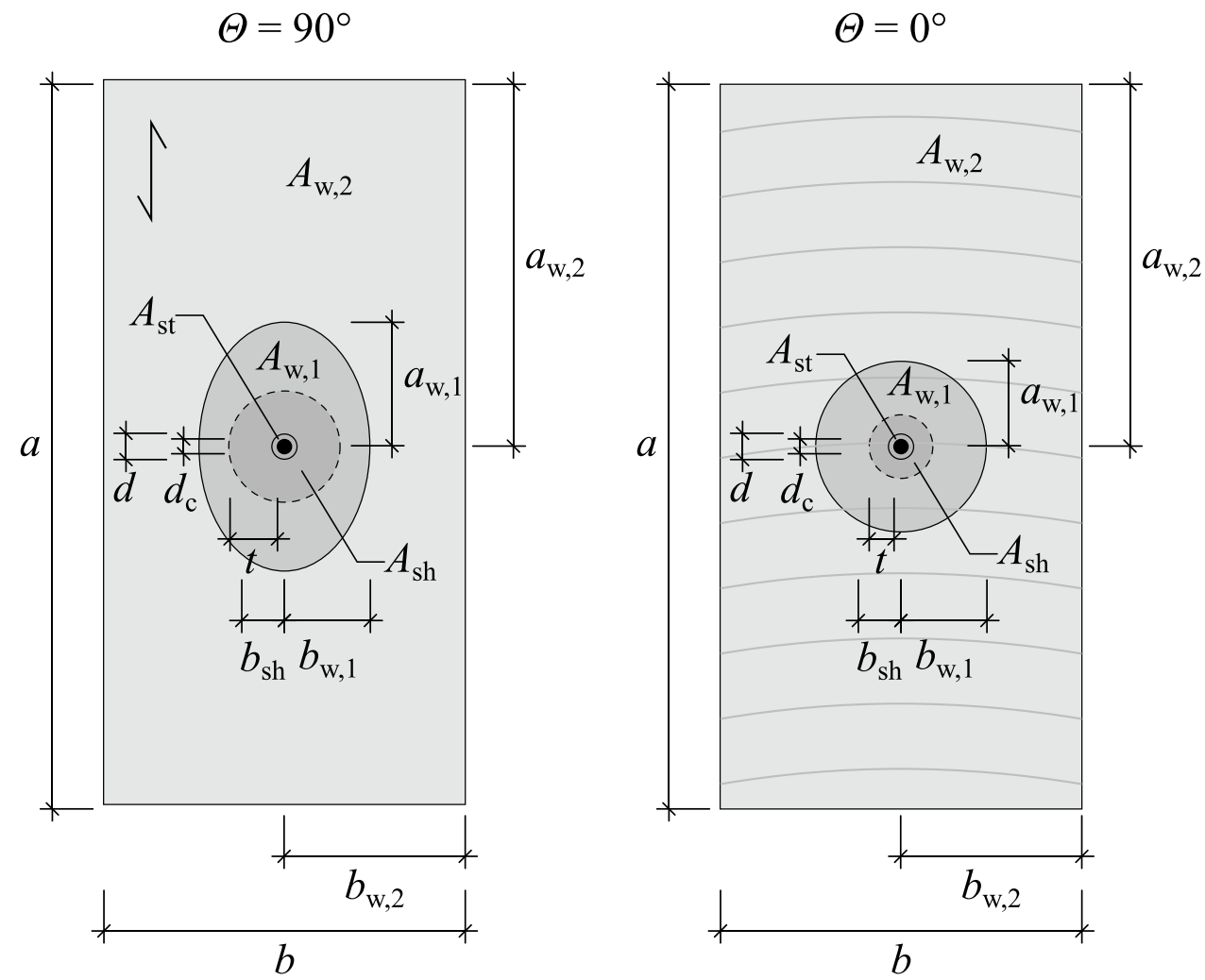
Fig. 13 Comparison of the mechanical model with the results of test series GLT27000 and GLT270-90 a, b axial forces along the screw axis, $\mathbf{c}, \mathbf{d}$ bond forces along the embedding length between the FBGs

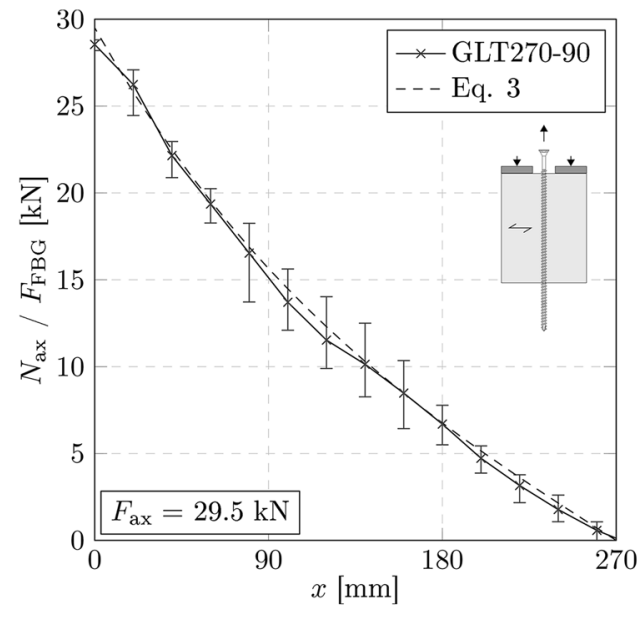

(a)

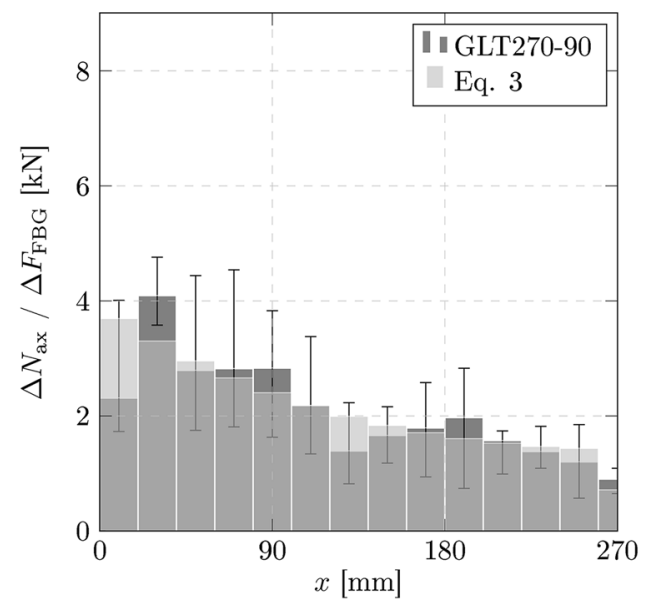

(c)

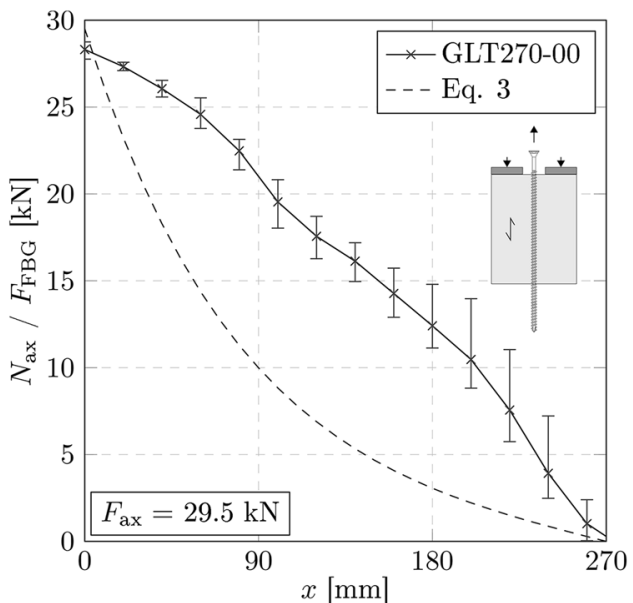

(b)

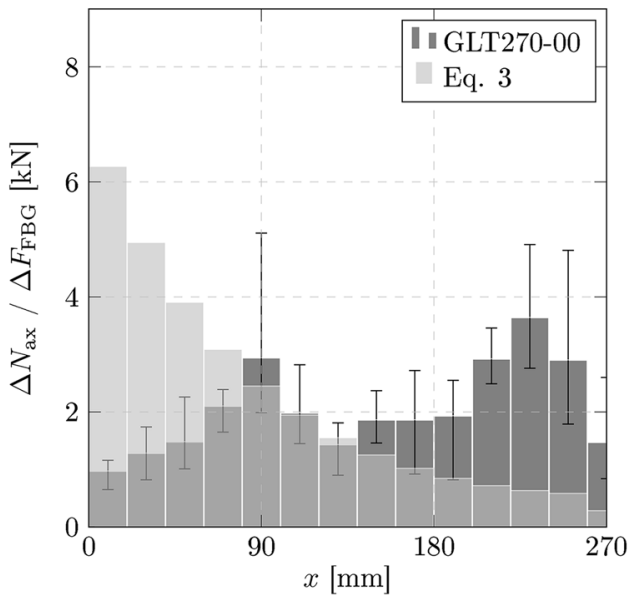

(d) axis. The sensor with 19 FBG load cells makes it possible to measure the force distribution along $360 \mathrm{~mm}$ of the threaded screw part.

A sensitivity analysis showed the influence of the load level and screw axis to grain angle on the development of axial forces along the screw.

Table 2 Material parameters and geometrical quantities

\begin{tabular}{llll}
\hline Parameter & Unit & $\begin{array}{l}\text { Test series } \\
\text { GLT270-00 }\end{array}$ & GLT270-90 \\
\hline$l_{\text {ef }}$ & $\mathrm{mm}$ & 270 & 270 \\
$\Theta$ & $\circ$ & 0 & 90 \\
$t$ & $\mathrm{~mm}$ & 14.5 & 22.0 \\
$G_{\mathrm{LT}} / G_{\mathrm{RT}}$ & $\mathrm{N} / \mathrm{mm}^{2}$ & 650 & 40 \\
$a_{\mathrm{w}, 1}$ & $\mathrm{~mm}$ & 36 & 36 \\
$b_{\mathrm{w}, 1}$ & $\mathrm{~mm}$ & 36 & 36 \\
$A_{\mathrm{w}, 1}$ & $\mathrm{~mm}$ & 4071 & 4071 \\
$E_{\mathrm{w}}$ & $\mathrm{N} / \mathrm{mm}^{2}$ & 11500 & 300 \\
$d_{\mathrm{c}}$ & $\mathrm{mm}$ & 7.1 & 7.1 \\
$A_{\mathrm{st}}$ & $\mathrm{mm}{ }^{2}$ & 39.6 & 39.6 \\
$E_{\mathrm{st}}$ & $\mathrm{N} / \mathrm{mm}^{2}$ & 210000 & 210000 \\
\hline
\end{tabular}

Furthermore, the support conditions of the test set-up and the material properties affect the interaction of the wood and the screw. Local peaks in the bond force were detected for different support conditions. The peaks can be explained by additional compression stresses in the interface between the screw and the timber. The position of the local peaks for a couple of pull-push test configurations might be explained by the load distribution angle depending on the screw to grain angle and the stiffness properties of the timber materials.

A comparison of results according to Volkersen's shearlag theory, assuming linear-elastic bond behaviour, showed good accordance for an embedding length $l=270 \mathrm{~mm}$ if the screw to grain angle is $90^{\circ}$. No such accordance between the model and the test results could be reached for a screw to the grain orientation of $0^{\circ}$. The model could be improved in the future considering nonlinear withdrawal deformation behaviour, as has already been performed for glued-in rods by Pörtner (2006).

Further investigations with the new measurement screw will focus on the load distribution of reinforcements made 
of self-tapping screws, for example, for beams with holes or notches. The effective embedding length will be determined experimentally from the force distribution inside the screw. Furthermore, the measuring system will be used to study the interaction of screws and the surrounding timber under changing environmental conditions. A first experimental study showed different axial load distribution inside the screw depending on the timber geometry and the type of loading.

Acknowledgements The authors would like to thank Jürgen Stork from Würth GmbH \& Co. KG, who supported this idea of a novel measurement screw from the beginning. Furthermore, MIOPAS GmbH, Goslar (Germany) supported the project with its experience in the field of fibre optic measurement and the production of an innovative optical sensors. The project would not have been feasible without the partners involved. Finally, we would like to thank our colleagues from TU Graz. The whole story started with their present to us of a screw equipped with a simple strain gauge.

Funding Open Access funding enabled and organized by Projekt DEAL.

Open Access This article is licensed under a Creative Commons Attribution 4.0 International License, which permits use, sharing, adaptation, distribution and reproduction in any medium or format, as long as you give appropriate credit to the original author(s) and the source, provide a link to the Creative Commons licence, and indicate if changes were made. The images or other third party material in this article are included in the article's Creative Commons licence, unless indicated otherwise in a credit line to the material. If material is not included in the article's Creative Commons licence and your intended use is not permitted by statutory regulation or exceeds the permitted use, you will need to obtain permission directly from the copyright holder. To view a copy of this licence, visit http://creativecommons.org/licenses/by/4.0/.

\section{References}

Aicher S, Gustafsson PJ, Wolf M (1999) In: Boström L (ed) Load displacement and bond strength of glued-inrods in timber influenced by adhesive, wood density, rod slenderness, and diameter. Stockholm, Schweden. RILEMPublications, France, pp 369-378

Ayoubi M, Trautz M (2013) Determination of the stress distribution in timber elements reinforced with self-tapping screws using an optical metrology system. Adv Mater Res 778:432-439. https:// doi.org/10.4028/www.scientific.net/AMR.778.432

Beijtka I (2005) Reinforcement of timber structures with self-tapping screws (in German: Verstärkung von Bauteilen aus Holz mit Vollgewindeschrauben). PhD Thesis, Karlsruher Institut für Technologie, Karlsruhe, Germany.

Bernasconi A (1996) Loading behaviour of wood perpendicular to the grain with different arrangements of shear and bending reinforcements (in German: Tragverhalten von Holz senkrecht zur Faserrichtung mit unterschiedlicher Anordnung der Schub- und Biegearmierung). PhD Thesis, ETH Zürich, Switzerland.

Blaß HJ, Beijtka I, Uibel T (2006) Load bearing capacity of connections with self-tapping screws (in German: Tragfähigkeit von Verbindungen mit selbstbohrenden Holzschrauben mit Vollgewinde). Karlsruher Institut für Technologie, Karlsruhe
Brandner R, Ringhofer A, Grabner M (2018) Probabilistic models for the withdrawal behavior of single self-tapping screws in the narrow face of cross laminated timber (CLT). Eur J Wood Prod 76:13-30. https://doi.org/10.1007/s00107-017-1226-3

Danzer M, Dietsch P, Winter S (2016) Reinforcement of round holes in glulam beams arranged eccentrically or in groups. In: Proceedings of the World Conference on Timber Engineering 2016, Vienna, Austria

Danzer M, Dietsch P, Winter S (2020) Shrinkage behaviour of reinforced glulam members. In: Proceedings 53-12-1 of the 53th INTER Meeting 2020, vol. 53-12-1, online

Dietsch P, Brandner R (2015) Self-tapping screws and threaded rods as reinforcement for structural timber elements-a stateof-the-art report. Constr Build Mater 97:78-89. https://doi.org/ 10.1016/j.conbuildmat.2015.04.028

Dietsch P, Kreuzinger H, Winter S (2013) Design of shear reinforcement for timber beams. In: Proceedings 46-7-9 of CIB-W18 Meeting, vol. 46-7-9, Vancouver, Canada

Ellingsbø P, Malo KA (2012) Withdrawal capacity of long selftapping screws parallel to grain direction. In: Proceedings of the World Conference on timber engineering (WCTE) 2012, Auckland, New Zealand

EN 14080 (2013) Timber structures-glued laminated timber and glued solid timber-requirements; German version EN 14080:2013. DIN German Institute for Standardization, Berlin

EN 384 (2019) Structural timber-determination of characteristic values of mechanical properties and density; German version EN 384:2016+A1:2018. DIN German Institute for Standardization, Berlin

ETA (2018a) ETA-11/0190: Self-tapping screws for use in timber constructions. European Technical Approval. Deutsches Institut für Bautechnik

ETA (2018b) ETA-14/0354: Glued laminated timber made of hardwood-structural laminated veneer lumber made of beech. European Technical Assessment. Austrian Institute of Construction Engineering

Eurocode 5 (2010) Design of timber structures-part 1-1: generalcommon rules and rules for buildings; German version EN 1995-1-1:2004 + AC:2006 + A1:2008. DIN German Institute for Standardization, Berlin

Frese M, Blaß HJ (2009) Models for the calculation of the withdrawal capacity of self-tapping screws. In: Proceedings 42-7-3 of the CIB-W18 Meeting, vol. 42-7-3, Dübendorf, Switzerland

Gehri E (2009) Influence of fasteners spacings on joint performance-experimental results and codification. In: Proceeding 42-7-8 of the CIB-W18 Meeting, vol. 42-7-8, Dübendorf, Switzerland

Gustafsson PJ, Serrano E (2000) Predicting the pull-out strength of glued-in rods. In: Proceedings of the 6th World Conference on Timber Engineering (WCTE), Whistler, Canada

Jensen JL, Nakatani M, Quenneville P, Walford B (2011) A simple unified model for withdrawal of lag screws and glued-in rods. Eur J Wood Prod 69:537-544. https://doi.org/10.1007/ s00107-010-0478-y

Jockwer R (2015) Structural behaviour of glued laminated timber beams with unreinforced and reinforced notches. PhD Thesis, ETH Zürich, Switzerland

Kumpenza C, Ringhofer A, Krenke T, Sotayo A, Pramreiter M, Mülller U (2020) Timber screw connection: study of the strain along the interface using optical measurement techniques and simulations. BioResources 15:3859-3873. https://doi.org/10.15376/ biores.15.2.3859-3873

Mahlknecht U, Brandner R, Augustin M (2016) Block shear failure mode of axially loaded groups of screws. In: Proceedings of the World Conference on Timber Engineering (WCTE) 2016, Vienna, Austria 
Naderer E, Franke S, Franke B (2016) Numerical simulation of reinforced timber structures perpendicular to the grain. Proceedings of the World Conference on Timber Engineering (WCTE) 2016 Vienna, Austria

Pirnbacher G, Brandner R, Schickhofer G (2012) Base parameter of self-tapping screws. In: Proceedings 42-7-1 of the CIB-W18 Meeting, vol. 42-7-1, Växjo, Sweden

Pörtner C (2006) Investigations concerning the bonding behaviour of glued-in fibreglass reinforcements and wood (in German: Untersuchungen zum Verbund zwischen eingeklebten stiftförmigen faserverstärkten Kunststoffen und Holz). PhD Thesis, University of Kassel, Germany

Ringhofer A, Schickhofer G (2014b) Influencing parameters on the experimental determination of the withdrawal capacity of selftapping screws. In: Proceedings of the World Conference on Timber Engineering (WCTE), Quebec, Canada

Ringhofer A, Schickhofer G (2014a) Investigations concerning the force distribution along axially loaded self-tapping screws. In: Aicher S, Reinhardt H-W, Garrecht H (eds) Materials and joints in timber structures. RILEM Bookseries 9. Springer, pp 201210. https://doi.org/10.1007/978-94-007-7811-5-19

Ringhofer A (2017) Axially loaded self-tapping screws in solid timber and laminated timber products. PhD Thesis, TU Graz, Austria

Schmidt-Thrö G, Scheufler W, Fischer O (2016) Continuous fibre optical strain measurement in reinforced concrete (in German:
Kontinuierliche faseroptische Dehnungsmessung im Stahlbetonbau). Beton Stahlbetonbau 111:496-504. https://doi.org/10. 1002/best.201600026

Serrano E (2001) Glued-in rods for timber structures-a 3D model and finite element parameter studies. Int J Adhes Adhes 21:115127. https://doi.org/10.1016/S0143-7496(00)00043-9

Tlustochowicz G, Serrano E, Steiger R (2011) State-of-the-art review on timber connections with glued-in steel rods. Mater Struct 44:997-1020. https://doi.org/10.1617/s11527-010-9682-9

Uibel T, Blaß HJ (2006) Load carrying capacity of joints with dowel type fasteners in solid wood panels. In: Proceedings 39-7-5 of the CIB-W18 Meeting, vol. 39-7-5, Florence, Italy

Volkersen O (1953) Load distribution in glued, riveted and bolted joints (in German: Die Schubkraftverteilung in Leim-, Nietund Bolzenverbindungen). Energie Tech 3:68-71 (5:103-108; 7:150-154)

Wolfthaler F, Augustin M (2016) Development of a measurement screw and application for laboratory tests and building monitoring. In: Proceedings of the World Conference on Timber Engineering (WCTE) 2016 Vienna, Austria

Publisher's Note Springer Nature remains neutral with regard to jurisdictional claims in published maps and institutional affiliations. 